\title{
SAFETY ENGINEERING, SECURITOLOGY AND INSOLVENCY
}

The basis of safety engineering is acceptance, introduction and maintenance of measures aimed at safety in various, mainly technical areas of human activities. Safety is a state during which there is an admissible probability of occurrence of damage to protected interests. Insolvency is a state of incapacity to pay. In the contribution, the specified definitions are developed, their mutual relations are shown and their connection with sustainable development theory and practice is emphasised.

\section{Introduction}

The aim of safety engineering as well as of securitology (i.e. a safety science) is elimination of threats. Insolvency is currently becoming a subject of contemplations and negotiations of not only politicians, economists and sociologists, insurance companies, entrepreneurs but also of ordinary people. It is so due to the fact that more and more entrepreneurial and non-entrepreneurial entities become insolvent. Municipalities and in a wider perspective even the whole states are not an exception.

\section{Insolvency like a Threat}

Insolvency, as a state of incapability to pay, is a threat not only for natural persons, legal entities entrepreneurs or non-entrepreneurs, but it also becomes a threat for entities of the state and public administration and whole countries, mainly the developing ones. Consequences of this insolvency, poverty and its overlooking, thus become a threat also for developed, rich societies.

Insolvency is a significant threat for implementation of sustainable development but not the only one. It is clear that development of society brings forward new sources of risks and increase of the intensity of risks already existing. The nature of these risks is based on undesirable effects of forces and phenomena with adverse consequences. In other words, it is damage to protected interests. [1]

The origin of the undesirable strengths and phenomena can be found either in nature or in human activities. Regardless of origin of these strengths and phenomena, their effects and consequences definitely deserve to be the subject of research. Also the problems of prevention of occurrence, mitigation of progress and elimination of impacts of these forces and phenomena deserve the same attention.

* Vladimir Klaban

Rasin University Brno, Czech Republic, E-mail: akademie@akademieops.cz
A huge increase of information and level of knowledge of human society significantly expanded possibilities of mankind, mainly in the technical area. The nature of human society has not changed too much. In last centuries we have seen an opinion that this development will get out of control of human power and due to its nature will lead to the end of mankind, or civilisation, if you want. One of the basic goals of the current developed society is the survival in a form of sustainable development.

Strictly speaking it is the protection of human society - or better said say (even though it is significantly narrowed) - of civilisation in our understanding, i.e. protection of the state security. We want to live in safe environment and thus we, as the mankind, deal with security aspects. Partial security issues in the whole number of areas are elaborated intensively - in other words, security research is being performed in the following areas, e.g.:

- Security of work;

- Security of transport;

- Personal security;

- Object security;

- Security of information;

- Safe filing of documents;

- Safe production technologies;

- Safe defence;

- Safe region;

- State security etc.

Most of the specified areas of safety research develops and examine adoption, implementation and maintenance of measures aimed at security in various, mainly technical areas of human activities. Security researches are theories for safety engineering the aim of which is practical implementation of measures leading to the ensuring of safety. 


\section{State security}

An extraordinary position among the areas of security research belongs to the state security. The issues of the state security is not considered to be a kind of safety engineering but many areas of safety engineering deal with practical performance of measures connected with the issues of the state security. We have to be aware of the fact that it is the well-functioning state that is obliged to create conditions for harmony between the needs of the people and the society, economic prosperity, healthy environment, social justice and health and life protection of people with regard to not damaging future generations.

It is possible to assume that perspectives of further development of the Czech Republic in the following period will be strongly determined by external and internal factors that will be very difficult to influence actively. Globally, tendencies that will influence the overall development in the EU and thus also Central European countries will be dominating.

From the assessment of the threats it is clear that in the middleterm perspective no massive military attack against the EU is probable. Deterioration of security situation on a global level has impacts also in the Euro-Atlantic area. Despite the fact that the security situation on the global level deteriorated, it has impacts also on security situation in the Euro-Atlantic area. This is reflected in threats that are difficult to foresee. Their occurrence and fast spreading is facilitated by globalisation. More and more often their originators are non-state actors (traditional and new terrorist organisations, radical religious, sectarian and extremist movements and groups) that purposefully threaten our lives.

The practice shows how difficult it is to foresee the threats The existence of various forces and elements trying to gain over the control, damage or eliminate various electronic, communication and information networks has been proved. There is a high risk of attacks of this kind. Extensive leaks of strategically important information or interference in the information systems of state institutions or businesses and companies ensuring the basic functions of the society and the state can threaten not only the strategic but also the vital interests of the EU states. [2]

The occurrence of threats is contributed by deepening imbalance between the North and the South. Economic and social slowdown of the South leads to dissatisfaction of its inhabitants. It creates breeding ground for radicalisation, extremism and terrorism. Dissatisfaction with living conditions leads to migration, often illegal one, to the countries in the North.

One of the thorniest problems the underdeveloped countries face is their astronomical indebtedness. Debts and the lack of capital arising from them restrict the access of the inhabitants to education and basic life needs and thus they also undermine the economic development.

Excessive indebtedness triggers and intensifies the economic, social and political problems of the debtor states. These problems can be seen in the pressure on export, elimination of social bene- fits, using of money from the development aid for settlement of debts, increasing unemployment, discouraging of investors, outflow of capital, destruction of the environment, growth of the poor class and increasing number of unsatisfied population of our planet.

The problem of insolvency and its consequences - growing poverty, lack of education, unavailable health care and suppression of the right for dignified life - does not only apply to poor countries, the consequences often have strong impacts also on more developed states of the North and they become threats for then. These consequences include:

- Increase of international polarisation and extremism - strengthening of the role of radical ideologies and violent tendencies, including international terrorism.

- Destroying of the environment- pressure on the growth of foreign exchange economy that would enable settlement of debts leads to massive destroying of the environment in many countries, which has global impacts.

- Increase of international crime - extending of sown areas for growing of drugs and increasing demand for them. Development of the international drug trade brings increase of grey and black economy and increase of international crime.

- Collapse of markets - collapse of the whole national economies in developing countries leads to decrease of markets also for companies from developed countries.

- Military conflicts - humanitarian crises drain the funds from the development cooperation and there is a growing need for expensive international military interventions.

- Influx of refugees - globally there is an increase in number of refugees trying to escape from the hopeless situation in their homes. It brings needs of further humanitarian interventions in the countries where the refugees move, there is growing xenophobia and violence.

The specified facts can be marked as threats that will not avoid even Central European states. We can assume that perspectives of further development in the following period will be strongly determined by the external and internal factors that will be very difficult to influence. In the period until the year 2015 (with an outlook until 2030) there will be dominating global tendencies which will also influence the overall development in the EU. They include mainly the following:

- Aging of the population and strengthening of migration from the countries of former Soviet Union, Near East and Middle East, Northern Africa, Asia with preconditions of creation of closed communities and subcultures outside the official control of the state.

- Outflow of investment means, mainly in favour of some countries in Asia with subsequent impacts on employment and social cohesiveness in the EU states.

- General and global deterioration of conditions of the access mainly to energy but also other raw materials. Continuous and unforeseeable growth of their prices and deterioration of their availability.

- Disturbing of traditional social connections and relations in the society with subsequent pressure on the change of social and political system. 
- Deterioration of military and political situation in the world with the emphasis on the region of the Near East and Middle East.

- Increase of number of critical situations induced by natural disasters and intentional or unintentional activities of people, with subsequent important impacts on the general situation within the EU.

- Deepening of vulnerability of the developed civilisation and various forms of into dependency [3].

\section{Safety Science as the Prevention}

Despite the above mentioned development tendencies seem to be irreversible at the moment, it is possible to take preventive measures and actions that will enable minimisation of their subsequent impacts. One of the important elements within the scope of timely and mainly efficient solution of these impacts is also purposeful solution of the issues of the population protection system. Protection of lives, health and material values, together with ensuring sovereignty, territory integrity and protection of democratic foundations, is one of the basic obligations and thus also functions of the state. This problem must become a subject matter of research of safety science.

It is also worth noticing that safety is characterised (determined) by and connected with the space, time and human society. We cannot speak about security without relation to people and human society.

Safety is thus always seen in connection with people and human society. The aim is to reach such a state in the particular area and time so that human society is not threatened as regards its health, life and property. From this point of view it is possible to deduce that safety is kind of a subjective philosophical category which only exists in connection with people.

Without analysing or criticising other interpretations, in the following text we will follow the definitions defined in the Longterm intention of research directions in the CR (LIRT) and use also in other works, [4] i.e.: "Security is a state during which there is admissible probability of occurrence of damage to protected interests". We consider this definition to be sufficiently general and fitting.

As we have already specified above, security is always seen in relation to people (humankind) and thus we can also define the protected interests.

Protected interests are human lives, health and property. When analysing this definition we will come to a conclusion that it is necessary to protect everything connected with health, lives and property of people. Naturally, it will be mainly the environment and infrastructure of human society.

With regard to a wide range and complexity of possible threats and dangers, growth of human population, technical development and increasing extrapolation of nature it is absolutely necessary for security to become a subject matter of scientific research.

Other attributes supporting our conviction that nowadays the "security" issues deserve establishment of security science and development of special security research are the following:

- Stage of human society development;

- Wide extent of knowledge in the areas dealing with security;

- Lack of arrangement and fragmentation of approaches to the individual items (particularities);

- Inexistence of general approaches and solutions;

- Necessity to improve the current system ensuring security.

Being aware of the fact that the term of security science will not be to the liking of many people, we will now attempt to show justifiability of the statement that research in the area of security can be considered to be a security research and that we can rightfully talk about security science.

Most of books dealing with the issues of science and research state that the basic preconditions for existence of a science (a field of science) are

- Subject of examination

- Examination methods.

In our case, the subject matter of examinations of security science is "security" in its general conception, i.e. a state when there is an admissible probability of occurrence of damage to protected interests, and suitable examination methods are for example the following:

- Extrapolation of tendencies;

- Scenario creation method;

- Economic analysis;

- Decision-making matrix;

- Operational research;

- Decision-making theory;

- Diagram of goals;

- Network methods;

- Historic analogy;

- Comparative method;

- Creation of hypotheses;

- Exercises, training, experiment.

We have to point out that examination methods develop and extend in time and with development of knowledge. For the area of security it will be interesting to use the "comparative method" based on the hypothesis that rudiments of what is developing and growing already existed in the past and nothing was created newly - mainly in relation to terrorist threats.

In the classification of sciences by T. G. Masaryk, security science can be included among practical sciences [5]. In this classification (based on Aristotle's classification), T. G. M. differentiates the following: 
- Theoretical sciences looking for the truth regardless its utilisation and having their organising principle in its subject matter (e.g. mathematics - quantity) and

- Practical sciences having their organising principle in the purpose outside the field of study and taking knowledge where and how it is offered to them by the theoretical sciences.

Practical sciences are built on theoretical sciences.

In the late $19^{\text {th }}$ century and in the course of the $20^{\text {th }}$ century a number of fields of science were established, which resulted from the intensive development of human society. As an example we can mention psychology, sociology, economy and political science.

Generalisation of knowledge in the area of security is possible and necessary. Thus also the requirement that a science must be sufficiently general will be fulfilled. However, there will be and must be mutual connections between other fields of science.

The current situation in the area of security is characterised by simplification of problems, the desire for creation of the lowest possible number of basic principles and forced unification and simplification of knowledge.

It is obvious that for the benefits of security science it will be necessary to conduct research and development work in a systematic way. In its document LIRT, the Research and Development Council of the CR specified seven thematic directions of the most important matter of the research: Sustainable development, Molecular biology, Energy sources, Material research, Competitive engineering, Information security and Information research. The term "research" is used to denominate systematic creative work extending knowledge, including knowledge of people, culture or society, by means of methods enabling confirmation, supplementing or disproval of gained knowledge performed as basic research, which consists of experimental or theoretical work performed with the aim to gain knowledge on the basis or nature of the examined phenomena, explanation of their causes and possible impacts of the use of the gained knowledge. This creative work is marked as the basic research, which includes experimental or theoretical work performed with the aim to gain new knowledge aimed at the future use in practice.

\section{Conclusion}

Security science dealing with research in favour of security is currently finding its place ?at both the specialist and lay public? and material, financial and institutional support. It is a correct way enabling implementation of sustainable development. We believe that the research programme "Security research" and solution of the partial programmes "Threats for critical infrastructure and Optimisation of relations of sustainable development and population protection", in the solution of which also the author of this contribution participates with the support from the Ministry of Interior, will contribute to the solution of the matter.

\section{References}

[1] KLABAN, V.: Insolvency - today phenomenon (in Czech), Reorganizace podniku a priprava noveho upadkoveho zakona, Brno, Rasin College, 2006, ISBN 978-80-87001-04-4.

[2] KLABAN, V.: Threats for critical infrastructure (in Czech), Proc. from $9^{\text {th }}$ specialist conference with international participation „Presence and future of crisis proceedings 2006“, Prague 2006, ISBN 80-239-7296-2.

[3] KLABAN, V.: Insolvency as a threat (in Czech), Proc. from conference Crisis management, UNI Pardubice, Lazne Bohdanec, 2007, ISBN 978-80-7194-951-0.

[4] KLABAN, V.: Safety science, security research and defence research (in Czech), Specialist conference with international participation "Interoperability in population defence management", University of Defence, Brno 2006, ISBN: 80-239-3503-10.

[5] MASARYK, T. G.: Selection from work (in Czech), published in 2001, translation Versuch einer concreten Logik, Klassification und Organisation der Wissenschaften (Vienna 1897). 